OPEN ACCESS

Edited by:

Li Wang,

Chinese Academy of Sciences

(CAS), China

Reviewed by:

Sabika Munikar,

Om Health Campus, Nepal

Si-Tong Chen,

Victoria University, Australia

*Correspondence:

Lucas Melo Neves

lucasmeloneves@uol.com.br

Specialty section:

This article was submitted to

Public Mental Health,

a section of the journal

Frontiers in Psychiatry

Received: 29 October 2021 Accepted: 26 November 2021 Published: 16 December 2021

Citation:

Souza KCd, Mendes TB, Gomes THS,

Silva AAd, Nali LHdS, Bachi ALL,

Rossi FE, Gil S, França CN and

Neves LM (2021) Medical Students

Show Lower Physical Activity Levels and Higher Anxiety Than Physical

Education Students: A

Cross-Sectional Study During the

COVID-19 Pandemic.

Front. Psychiatry 12:804967.

doi: 10.3389/fpsyt.2021.804967

\section{Medical Students Show Lower Physical Activity Levels and Higher Anxiety Than Physical Education Students: A Cross-Sectional Study During the COVID-19 Pandemic}

\author{
Karla Cardoso de Souza ${ }^{1}$, Tassia Barcelos Mendes ${ }^{1}$, Tabatah Hellen Santos Gomes ${ }^{2}$, \\ Ariana Aline da Silva ${ }^{1}$, Luiz Henrique da Silva Nali ${ }^{2}$, Andre Luis Lacerda Bachi ${ }^{2}$, \\ Fabricio Eduardo Rossi ${ }^{3}$, Saulo Gil ${ }^{1}$, Carolina Nunes França ${ }^{2}$ and Lucas Melo Neves ${ }^{2,4 \star}$ \\ ${ }^{1}$ Santo Amaro University, São Paulo, Brazil, ${ }^{2}$ Post-Graduation Program in Health Sciences, Santo Amaro University, São \\ Paulo, Brazil, ${ }^{3}$ Immunometabolism of Skeletal Muscle and Exercise Research Group, Department of Physical Education and \\ Professor at Graduate Program in Science and Health, Federal University of Piauí (UFPI), Teresina-PI, Brazil, ${ }^{4}$ Bipolar \\ Disorder Program (PROMAN), Department of Psychiatry, University of São Paulo Medical School, São Paulo, Brazil
}

Objective: This study aimed to compare the time in physical activity (PA) [light (LPA), moderate and vigorous (MVPA)] and sedentary behavior (SB) (weekdays, weekends, or both) between Medical (MED) and Physical Education (PE) students who underwent remote classes imposed by the COVID-19. In addition, we compared symptoms of depression and anxiety and sleep quality.

Methods: A cross-sectional study (272 MED and 95 PE students). The International Physical Activity Questionnaire (IPAQ), Beck Inventory (Anxiety, Depression), and Pittsburgh Sleep Quality were used to assess PA and SB, anxiety and depression symptoms, and quality of sleep, respectively. The data are presented as median and interquartile intervals 25-75.

Results: We observed statistically significant differences between MED and PE students for MVPA [MED: 165 min per week (0-360) vs. PE: 420 min per week (180-670), $p<$ 0.001 ], SB Total [MED: $10 \mathrm{~h}$ per day (8-12) vs. PE: $7 \mathrm{~h}$ per day (5-10), $p<0.001)$ ], and anxiety symptoms [MED: 13 points (5-23) vs. PE: six points (2-16), $p<0.001)$ ].

Conclusion: Together, our findings indicate that MED students spent less time in MVPA and more time in SB than PE students. MED students also presented worse mental health in the pandemic situation imposed by the COVID-19.

Keywords: sedentary behavior, university, exercise, coronavirus - COVID-19, student

\section{INTRODUCTION}

The COVID-19 pandemic (1) led the world population to adopt preventive measures, such as hygiene habits, and to maintain social distancing and home isolation to control the spread of the virus. In this scenario, common activities were drastically affected, such as work routine, (2) leisure-related activities (3), and regular classes at schools and universities (4).

Home isolation may impact levels of physical activity (PA, defined as activity that gets your body moving, to increase energy expenditure above resting levels) (5) and sedentary behavior 
(SB, defined as waking behavior characterized by an energy expenditure $\leq$ of 1.5 metabolic equivalents, while in a sitting, reclining, or lying posture) (6). Indeed, recent data showed that PA and SB were drastically affected by the COVID-19 pandemic (7). This scenario was inevitable due to the lack of vaccinations early in the pandemic.

PA and SB are associated with mental health and sleep quality (8). For example, high levels of PA are related to lower symptoms of depression and anxiety (9) and greater sleep quality (10). On the other hand, elevated SB is associated with depression and anxiety symptoms (11). Furthermore, home isolation due to the COVID-19 pandemic has been related to worsening mental health in the general population $(12,13)$. Moreover, negative mental alterations such as depression and anxiety symptoms may lead to a poor physical activity-related lifestyle (e.g., lower PA and higher SB), establishing a "vicious cycle" among these conditions $(11,14)$.

Students were drastically affected by the COVID-19 pandemic since education systems adopted remote classes. Under normal conditions, most university students already did not meet the recommendation of $\mathrm{PA}$ and spent approximately $7-8 \mathrm{~h}$ per day in SB (15). In the same way, we observed that more than two thirds of Brazilian medical students did not meet the recommendation of $\mathrm{PA}$ and spent more than $8 \mathrm{~h}$ per day in SB during the pandemic (14). This poor physical activity-related lifestyle may impair sleep quality and increase the depression and anxiety symptoms commonly observed in MED students $(16,17)$. Interestingly, most Brazilian physical education (PE) students meet physical activity recommendations (18). In fact, a recent meta-analysis (15 studies, 3,245 students) indicates that between two-thirds and all (71 to 100\%) Brazilian PE meet PA recommendations.

Although it is still possible to speculate that the PA and SB of PE students were negatively influenced during the COVID19 pandemic, in the same way as MED students, due to the change from regular classes to remote classes. On the other hand, despite the possible negative impact of the pandemic on PA and $\mathrm{SB}$, engagement of $\mathrm{PE}$ students in the practical demands related to the physical education classes characteristic of their course and associated internships, may confer some advantage compared to MED students. However, this assumption still needs to be elucidated.

Another important point related to the routines of MED students is activities to assist the population during a pandemic, particularly students enrolled in the second half of the course $\left(6^{\text {th }}\right.$ to $12^{\text {th }}$ semesters). Furthermore, lack of resources and staffing, coupled with reduced staff numbers through contamination with the virus, may have further increased the stressful situations related to medical work demand (19). In this scenario, it is reasonable to assume that MED students from different semesters may present distinct mental health, as well as different times of $\mathrm{PA}$ and SB due to time taken with patient care. Therefore, it is feasible to compare the first half of the course with the second half of the course.

Thus, the current study aimed to compare the levels of PA [light (LPA), moderate and vigorous (MVPA)] and SB (on weekdays, weekends, or both) between MED and PE students who underwent remote classes, imposed due to the COVID19 pandemic. In addition, we compared depression and anxiety symptoms and sleep quality of MED and PE students, and the first and second halves of the courses. We hypothesized that MED students would spend less time in PA and more time in SB and demonstrate worse mental health than PE students, with differences between the first and second halves of the MED course.

\section{METHODS}

\section{Study Design and Participants}

This is a cross-sectional study, which was approved by the local Ethics and Research Committee (approval number: 4.049.214), and followed the precepts of the Declaration of Helsinki. The data were collected between September 2020 and February 2021. All students agreed and signed the consent form. Students aged $\geq 18$ years from MED ( $1^{\text {st }}$ to $12^{\text {th }}$ semester) and PE $\left(1^{\text {st }}\right.$ to the $8^{\text {th }}$ semester) were invited to participate in the study. Participants were contacted via message application or e-mail. If the participant agreed to participate, they were sent an online form containing the consent form and questionnaires to assess demographic characteristics, $\mathrm{PA}, \mathrm{SB}$, depression and anxiety symptoms, and sleep quality. For better comprehension of the collected information, initially, the student representative of the groups (WhatsApp group administrator) sent the research questionnaire link directly to the WhatsApp group. After 4 days, the authors (TB and $\mathrm{KC}$ ) were added to these WhatsApp groups and again sent the research questionnaire link and were available to clarify any doubts. Of 1,400 students from 30 distinct classes contacted, 367 students (MED: $272=27 \%$ of all MED students; PE: $95=24 \%$ of all PE students) answered the questionnaire. No students directly stated that they did not want to participate in the survey. Despite the groups being unbalanced, we emphasize that, in percentage terms, $\sim 25 \%$ of the students in each course were evaluated.

\section{Demographic Characteristics and Self-Perception During the COVID-19 Pandemic}

A questionnaire was included to collect data on age, sex, semester of the course, the city lived in before enrolling on the course, the practice of a physical exercise program, COVID-19 diagnosis, use of tobacco and alcohol, and questions about self-perception of worsening of the level of PA and SB during the period of the COVID-19 pandemic.

\section{Sample Size Calculation}

The sample size was determined using G-Power software (version 3.1.2 - Universitat Kiel, Germany), inputting an $\alpha$ error (0.05) and power $(1-\beta$ error $=0.90)$. Since the literature is scarce concerning comparisons of $\mathrm{PA}$ and $\mathrm{SB}$ between MED and $\mathrm{PE}$ students, we assumed an arbitrary moderate effect size (Cohen' d) of 0.4. Calculations were based on an independent $t$-test, and the total sample size was determined 180 patients (i.e., 90 students in each group). 


\section{Measures \\ Physical Activity and Sedentary Behavior Assessment}

The times of PA (LPA, MVPA) and SB (weekdays, weekends, or both) were assessed by the International Physical Activity Questionnaire (IPAQ), which contains eight questions about PA and SB considering the routine of the previous seven days. This tool is widely used and validated for the Brazilian population (20). The IPAQ shows good reliability (Spearman correlation coefficients $=0.80$ ) and test-retest reliability (Spearman correlation coefficients $=0.80$ ), and presents high correlations with other measures of physical activity (accelerometer $=0.70$ to 0.80$)(21)$.

\section{Anxiety and Depression Symptom Assessment}

Anxiety and depression symptoms were assessed by the Beck Anxiety Inventory (BAI) and Beck Depressive Inventory (BDI) $(22,23)$, which are composed of 21 multiple-choice statements, each with four possible responses $(0-3)$. Thus, the final score ranges from 0 to 63 points. The BAI shows good reliability (Cronbach's alpha coefficient $=0.95$ ) and test-retest reliability (Pearson's $r=0.73$ to 0.96 ), and presents high correlations with other measures of anxiety (State-Trait Anxiety Inventory $=0.58$; Diary Anxiety $=0.54$ ) (24). The BAI is a widely used tool, validated for the Brazilian population (25). The cut-off point adopted to identify symptoms of low and high anxiety followed that shown in a previous study (26): $<13$ points (low anxiety symptoms) and $\geq 13$ points (high anxiety symptoms).

The BDI is also a validated tool for the Brazilian population (27) and shows good reliability (Cronbach's alpha coefficient $=$ 0.85 ) and test-retest reliability (Pearson's $r=0.76$ ), and presents high correlations with other measures of depression, including the Center for Epidemiologic Studies of Depression (Pearson's $r=0.66-0.86)$ and Hamilton Rating Scale for Depression (Pearson's $r=0.66-0.75$ ) (28). The cut-off point adopted to identify symptoms of low and high depression followed that shown in previous studies (29): $<10$ points (symptoms of low depression) and $\geq 10$ points (symptoms of high depression).

\section{Sleep Assessment}

Sleep quality was assessed by the Pittsburgh Sleep Quality Index (PSQI), validated for the Brazilian population (30). The PSQI contains questions about the subject's sleep habits during the previous month. For example, bedtime, time to fall asleep, time to wake up, and actual h of sleep, in addition to the frequency $(1,2$, or 3 times a week) of difficulty falling asleep in $30 \mathrm{~min}$, waking up at night/dawn, getting up at night to go to the bathroom, difficulty breathing, coughing, snoring, cold, heat, nightmares, other reasons. The final score ranges from 0 to 21 points. The measure consists of 19 individual items, creating seven components (Subjective sleep quality; Sleep latency; Sleep duration; Habitual sleep efficiency; Sleep disturbances; Use of sleeping medication; Daytime dysfunction) and a Global PSQI score (sum of the 7 components). The PSQI shows good reliability (Cronbach's alpha coefficient $=0.82$ ) $(31)$ and testretest reliability (a intraclass correlation coefficient $=0.81$ ) (32), and presents high correlations with other measures of sleep quality (i.e., clinical diagnosis of insomnia, the ISI score, some variables of polysomnography) (32). In addition, the most commonly reported cut-off point for MS in a recent metaanalysis (33) was adopted: $<6$ points (good sleep quality) and $\geq 6$ points (poor sleep quality).

\section{Statistical Analysis}

Data are presented as mean (standard deviation), or median and interquartile range (IQR) for continuous variables. Categorical variables are shown as absolute and frequencies (\%). Normality and equality of variances were tested using the KolmogorovSmirnov test and Levene test, respectively. Non-parametric data are shown as median and interquartile range (IQR: 25 - 75). The Mann-Whitney test was used to assess differences between groups (PE and MED) and between the first and second halves of the courses $\left(1^{\text {st }}\right.$ to $4^{\text {th }}$ and $5^{\text {th }}$ to $8^{\text {th }}$ in PE; $1^{\text {st }}$ to $6^{\text {th }}$ and $7^{\text {th }}$ to $12^{\text {th }}$ in MED). Logistic regression models were used to evaluate the association between course (MED or PE), and dichotomous variables: MVPA ( $<300 \mathrm{~min}$ per week vs $\geq 300 \mathrm{~min}$ per week), $\mathrm{SB}$ ( $<$ than $8 \mathrm{~h}$ vs $\geq$ than $8 \mathrm{~h}$ ). Additionally, the association between course (MED or PE) and continues variables: anxiety symptoms (points of BAI), depression symptoms (points of BDI), and sleep quality (points of PSQI) were evaluated. Results from the logistic regression models were presented as odds ratios (ORs). The presence of relationships between numerical variables (MVPA, SB, Anxiety and Depression symptoms, and, Sleep Quality), was examined with the Spearman Correlation Test. Data were analyzed using IBM SPSS Statistics, version 22 (SPSS Inc., Chicago, IL, USA). The significance level was set at $\mathrm{P} \leq 0.05$.

\section{RESULTS}

Table 1 details the main sample characteristics. In brief, 1,400 students from 30 distinct classes were contacted, of which 367 students (MED: 272; PE: 95) answered the questionnaire and were included in the analysis. The sample of MED students was predominantly composed of females (79\%), while the sample of PE students was composed mainly of males (63\%). The median ages for MED and PE students were 21 and 25 years, respectively. Sixty-seven percent $(67 \%)$ of the MED students were inactive ( $<300 \mathrm{~min}$ per week), compared to only thirty-four percent (34\%) of the PE students. Seventy-nine percent (79\%) of the MED students and $57 \%$ of the PE students reported spending more than $8 \mathrm{~h}$ in SB.

Table 2 presents a comparison between $\mathrm{MED}$ and $\mathrm{PE}$ students regarding the sleep variable PSQI. Considering the Global PSQI score, we did not verify a significant difference between the groups $(p>0.05)$. However, when comparing specific components of PSQI, we observed greater scores in sleep duration and habitual sleep efficiency for MED students compared to PE students (both $p<0.05$ ). On the other hand, $\mathrm{PE}$ students showed greater scores for use of sleeping medication and daytime dysfunction than MED students (both $p<0.05$ ).

Figure 1 presents the comparisons between MED and $\mathrm{PE}$ students regarding: panel A - Anxiety symptoms (BAI); panel B - Depression symptoms (BDI); panel C - Light physical activity; panel D - Moderate and vigorous physical activity; panel E - 
TABLE 1 | Sample characteristics of medical (MED) and physical education (PE) students.

\begin{tabular}{|c|c|c|}
\hline Variable & MED $(N=272)$ & PE $(n=95)$ \\
\hline Age (years) & $21.0(19.3-23.0)$ & $25.3(20.0-30.0)$ \\
\hline Sex & 215 (79\%) & 35 (36.8\%) \\
\hline \multicolumn{3}{|l|}{ Female } \\
\hline Male & $57(21 \%)$ & $60(63.2 \%)$ \\
\hline $\begin{array}{l}\text { The first half of the courses } \\
\text { (1 }{ }^{\text {st }} \text { to } 4^{\text {th }} \mathrm{PE} \text { or } 1^{\text {st }} \text { to } 6^{\text {th }} \mathrm{MED} \text { ) }\end{array}$ & $221(81.2 \%)$ & $53(55.8 \%)$ \\
\hline $\begin{array}{l}\text { The second half of the courses } \\
\left(5^{\text {th }} \text { to } 8^{\text {th }} \mathrm{PE} \text { or } 7^{\text {th }} \text { to } 12^{\text {th }} \mathrm{MED}\right)\end{array}$ & $51(18.8 \%)$ & $42(44.2 \%)$ \\
\hline $\begin{array}{l}\text { MVPA } \\
\text { Physically inactive (<300 min per week) }\end{array}$ & $184(67.7 \%)$ & $33(34.8 \%)$ \\
\hline Physically active ( $\geq 300$ min per week) & $89(32.3 \%)$ & $62(65.2 \%)$ \\
\hline $\begin{array}{l}S B \geq \text { than } 8 h \\
\text { Yes }\end{array}$ & $216(79.4 \%)$ & $55(57.9 \%)$ \\
\hline No & $66(20.6 \%)$ & $40(42.1 \%)$ \\
\hline
\end{tabular}

Have you performed systematic physical exercises in the last 6 months? (This includes weight training, swimming, dancing, or any other type of activities, performed as part of your routine)

\begin{tabular}{|c|c|c|}
\hline Yes & $181(66.5 \%)$ & $74(77.9 \%)$ \\
\hline No & $91(33.5 \%)$ & $21(22.1 \%)$ \\
\hline $\begin{array}{l}\text { Anxiety symptoms } \\
0 \text { to } 12 \text { points (low anxiety symptoms *) }\end{array}$ & 135 (49.6\%) & $73(76.8 \%)$ \\
\hline$>12$ points (high anxiety symptoms *) & 137 (50.4\%) & $22(23.2 \%)$ \\
\hline $\begin{array}{l}\text { Depression symptoms } \\
0 \text { to } 10 \text { points (low depression symptoms **) }\end{array}$ & $132(48.5 \%)$ & $59(62.1 \%)$ \\
\hline >10 points (elevated depression symptoms ${ }^{\star \star}$ ) & $140(51.5 \%)$ & $36(37.9 \%)$ \\
\hline $\begin{array}{l}\text { Sleep quality } \\
\text { Good sleep quality (<6 points) }{ }^{* \star *}\end{array}$ & $125(46.0 \%)$ & $53(55.8 \%)$ \\
\hline Poor sleep quality ( $\geq 6$ points) ${ }^{\star \star \star}$ & $147(54.0 \%)$ & $42(44.2 \%)$ \\
\hline $\begin{array}{l}\text { Have you had a COVID-19 diagnosis? } \\
\text { Yes }\end{array}$ & $30(11.0 \%)$ & $16(16.8 \%)$ \\
\hline & 242 (89.0\%) & 79 (83.2\%) \\
\hline
\end{tabular}

Do you consider that the COVID-19 pandemic changed your level of physical activity and SB?

$\begin{array}{lcc}\text { Yes } & 226(83.1 \%) & 64(67.4 \%) \\ \text { No } & 46(16.9 \%) & 31(32.6 \%)\end{array}$

Do you consider that the COVID-19 pandemic changed your level of anxiety symptoms?

$\begin{array}{lcc}\text { Yes } & 220(80.9 \%) & 56(58.9 \%) \\ \text { No } & 52(19.1 \%) & 39(41.1 \%)\end{array}$

Do you consider that the COVID-19 pandemic changed your level of depression symptoms?

$\begin{array}{lcc}\text { Yes } & 150(55.1 \%) & 32(33.7 \%) \\ \text { No } & 122(44.9 \%) & 63(66.3 \%) \\ \text { Do you use cigarettes? } & 40(14.7 \%) & 6(6.3 \%) \\ \text { Yes } & & \\ \text { No } & 232(85.3 \%) & 89(93.7 \%) \\ \text { Do you use alcohol? } & 180(66.2 \%) & 41(43.2 \%) \\ \text { [0.5pt] Yes } & & \\ \text { No } & 92(33.8 \%) & 54(56.8 \%)\end{array}$

SB, sedentary behavior; MVPA, moderate and vigorous physical activity; 'Based on the cut-off of Sæmundsson et al. (26). "*k Based on the cut-off of Gomes et al. (27). " Based on the cut-off of Rao et al. (33).
TABLE 2 | Comparison between Medicine and Physical Education students regarding the sleep variable Pittsburgh Sleep Quality Index.

\begin{tabular}{|c|c|c|c|}
\hline PSQI Components & $\begin{array}{l}\text { Medicine students } \\
\quad(N=272) \\
\text { Median - Q1-Q3 }\end{array}$ & $\begin{array}{l}\text { Physical Education } \\
\text { students } \\
(N=95) \\
\text { Median - Q1-Q3 }\end{array}$ & $p$-value \\
\hline Subjective sleep quality & $1(1-2)$ & $1(1-2)$ & 0.707 \\
\hline Sleep latency & $2(1-2)$ & $1(1-2)$ & 0.173 \\
\hline Sleep duration & $1(0-2)$ & $2(0-2)$ & 0.058 \\
\hline $\begin{array}{l}\text { Habitual sleep } \\
\text { efficiency }\end{array}$ & $0(0-1)$ & $0(0-1)$ & 0.022 \\
\hline Sleep disturbances & $1(1-1)$ & $1(1-1)$ & 0.569 \\
\hline $\begin{array}{l}\text { Use of sleeping } \\
\text { medication }\end{array}$ & $0(0-0)$ & $0(0-0)$ & $<0.001$ \\
\hline Daytime dysfunction & $1(1-2)$ & $1(0-2)$ & $<0.002$ \\
\hline Global PSQI score & $7(4-10)$ & $7(4-10)$ & 0.509 \\
\hline
\end{tabular}

All PSQI components are presented in total points (0-3). Global PSQI score presented in total points (0-21). PSQI, Pittsburgh Sleep Quality Index.

Sedentary behavior days of week; panel F - Sedentary behavior days of the weekend; panel G - Sedentary behavior total.

The MED students presented worse scores related to anxiety symptoms [median above the cut-off for high anxiety symptoms - >12 points - SÆMUNDSSON et al. (2011)] (26), physical activity - LPA and MVPA (median lower than recommendation of 300 min per week), and SB days of week and total (more than $8 \mathrm{~h}$ per day) in comparison to PE students.

Table 3 presents a comparison (Mann-Whitney Test) between the first and second halves of the courses $\left(1^{\text {st }}\right.$ to $4^{\text {th }}$ and $5^{\text {th }}$ to $8^{\text {th }}$ in PE; $1^{\text {st }}$ to $6^{\text {th }}$ and $7^{\text {th }}$ to $12^{\text {th }}$ in MED) regarding anxiety symptoms (BAI), depression symptoms (BDI), and variables related to the level of physical activity (LPA and MVPA) and SB (week, weekend, and total).

The first and second halves of the courses $\left(1^{\text {st }}\right.$ to $4^{\text {th }}$ and $5^{\text {th }}$ to $8^{\text {th }}$ in PE; $1^{\text {st }}$ to $6^{\text {th }}$ and $7^{\text {th }}$ to $12^{\text {th }}$ in MED) did not present differences for anxiety and depression symptoms, physical activity (LPA and MVPA), and SB (week, weekend, and total). Furthermore, for sleep quality (PSQI), we did not verify differences between the first and second halves of the course in $\operatorname{MED}\left(1^{\text {st }}\right.$ to $6^{\text {th }}$ and $7^{\text {th }}$ to $\left.12^{\text {th }}\right)$, but differences were verified between the first and second halves of the course in PE ( $1^{\text {st }}$ to $4^{\text {th }}$ and $5^{\text {th }}$ to $8^{\text {th }}$ ), for sleep latency and sleep disturbances.

Table 4 presents a logistic regression association of course (MED or PE) and meeting the MVPA recommendation, accumulated $<8 \mathrm{~h}$ of SB, High Anxiety symptoms ( $<12$ points), High Depression symptoms ( $<10$ points), and Poor Sleep Quality ( $\geq 6$ points).

The course was associated with an increase in meeting MVPA recommendations $(\mathrm{OR}=3.87,95 \% \mathrm{CI} 2.27-6.59 p<0.001)$ and a decrease in reporting $>8 \mathrm{~h}$ per day of $\mathrm{SB}(\mathrm{OR}=0.28,95 \% \mathrm{CI}$ $0.17-0.47 p<0.001$.

Table 5 presents a relationship (Spearman Correlation) between MVPA, SB, Anxiety symptoms, Depression symptoms, and Sleep Quality. 


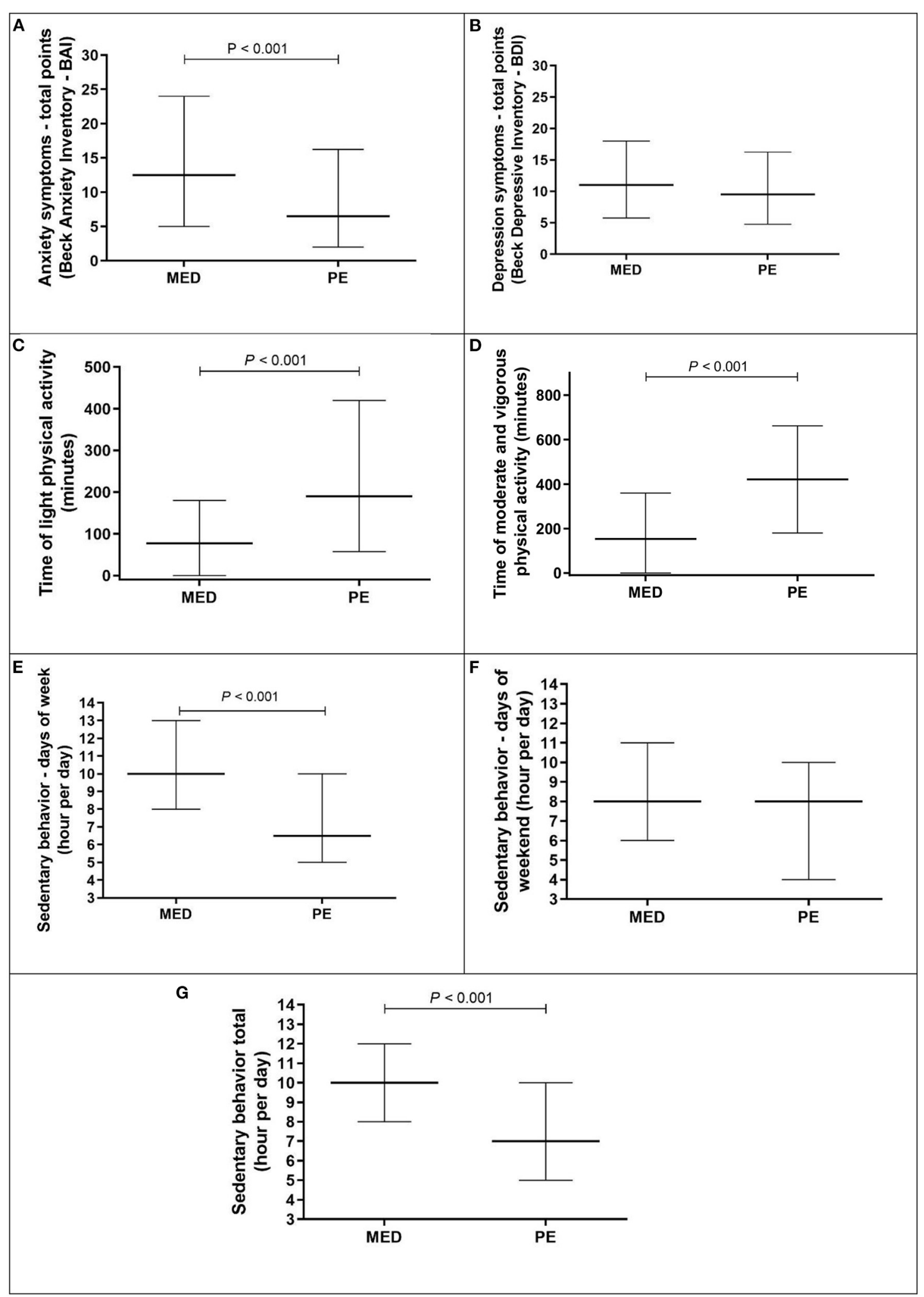

FIGURE 1 | Comparison between medical (MED) and physical education (PE) student regarding anxiety symptoms, depression symptoms, time of light, moderate and vigorous physical activity, and time of sedentary behavior (week, weekend, and total). Data present in median and interval interquartile (25-75). Anxiety Symptoms and Depression symptoms present in total points (0-63). LPA and MVPA are present in minutes per week. Sedentary behavior of week, weekend, and Total are present in hour per day. Panel A - Anxiety symptoms (BAI); panel B - Depression symptoms (BDI); panel C - Light physical activity; panel D - Moderate and vigorous physical activity; panel E - Sedentary behavior days of week; panel F - Sedentary behavior days of the weekend; panel G - Sedentary behavior total. 
TABLE 3 | Comparisons (Mann-Whitney Test) between the first and second halves of the courses (1st to 4th and 5th to 8th in PE; 1st to 6th and 7th to 12th in MED) regarding anxiety symptoms (Beck Anxiety Inventory - BAI), depression symptoms (Beck Depressive Inventory - BDI), level of physical activity and sedentary behavior (IPAQ).

\begin{tabular}{|c|c|c|c|c|c|c|}
\hline & \multicolumn{2}{|c|}{$\begin{array}{l}\text { Medicine students } \\
\qquad(N=272) \\
\text { Median - Q1-Q3 }\end{array}$} & \multirow[t]{2}{*}{ p-value } & \multicolumn{2}{|c|}{$\begin{array}{l}\text { Physical Education students } \\
\qquad(N=95) \\
\text { Median - Q1-Q3 }\end{array}$} & \multirow[t]{2}{*}{$p$-value } \\
\hline & $\begin{array}{l}\text { The first half of the } \\
\text { course }(N=221)\end{array}$ & $\begin{array}{l}\text { The second half of } \\
\text { the course }(N=51)\end{array}$ & & $\begin{array}{l}\text { The first half of the } \\
\text { course }(N=53)\end{array}$ & $\begin{array}{l}\text { The second half of } \\
\text { the course }(N=42)\end{array}$ & \\
\hline Anxiety Symptoms & $13(6-24)$ & $11(4-21)$ & 0.079 & $10(2-19)$ & $5(2-12)$ & 0.074 \\
\hline Depression symptoms & $11(5-18)$ & $12(6-16)$ & 0.746 & $11(4-18)$ & $9(4-13)$ & 0.329 \\
\hline LPA & $90(50-240)$ & $60(40-150)$ & 0.451 & $150(80-410)$ & $180(82-420)$ & 0.735 \\
\hline MVPA & $160(80-360)$ & $180(450)$ & 0.652 & $420(180-725)$ & 470 (202-660) & 0.831 \\
\hline SB week & $10(8-13)$ & $10(8-12)$ & 0.723 & $6(4-10)$ & $7(5-10)$ & 0.299 \\
\hline SB weekend & $8(5-11)$ & $10(7-12)$ & 0.057 & $6(4-10)$ & $8(4-13)$ & 0.442 \\
\hline SB Total & $9(7-12)$ & $10(8-13)$ & 0.653 & $6(4-9)$ & $7(5-10)$ & 0.221 \\
\hline Subjective sleep quality & $1(1-2)$ & $1(1-2)$ & 0.363 & $1(1-2)$ & $1(1-2)$ & 0.063 \\
\hline Sleep latency & $2(1-2)$ & $1(1-3)$ & 0.846 & $2(1-2)$ & $1(0-2)$ & 0.033 \\
\hline Sleep duration & $1(1-2)$ & $1(1-2)$ & 0.152 & $2(1-2)$ & $2(1-2)$ & 0.633 \\
\hline Habitual sleep efficiency & $1(1-2)$ & $1(1-2)$ & 0.488 & $1(0-1)$ & $1(0-1)$ & 0.658 \\
\hline Sleep disturbances & $1(1-1)$ & $1(1-1)$ & 0.389 & $1(1-2)$ & $1(1-1)$ & 0.003 \\
\hline Use of sleeping medication & $1(1-2)$ & $1(1-2)$ & 0.703 & $1(0-2)$ & $1(0-2)$ & 0.927 \\
\hline Daytime dysfunction & $1(1-2)$ & $1(1-2)$ & 0.746 & $1(0-2)$ & $1(0-1)$ & 0.314 \\
\hline Global PSQI score & $7(4-10)$ & $7(4-11)$ & 0.079 & $7(5-10)$ & $6(3-9)$ & 0.069 \\
\hline
\end{tabular}

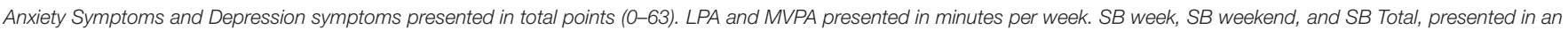

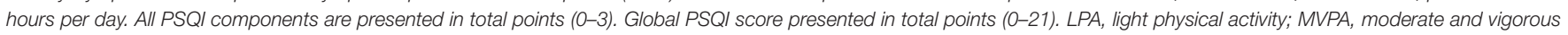
physical activity; SB, sedentary behavior; PSQI, Pittsburgh Sleep Quality Index.

TABLE 4 | Regression logistic association of course (MED or PE) and meet MVPA recommendation, accumulated $<8$ h of SB, Anxiety symptoms ( $<12$ points), Depression symptoms ( $<10$ points), and Poor Sleep Quality ( $\geq 6$ points).

\begin{tabular}{lcccc}
\hline & OR & $\mathbf{9 5 \%} \mathbf{C l}$ & \multicolumn{1}{c}{$\boldsymbol{p}$} \\
\hline MVPA & 3.87 & 2.27 & 6.59 & $<0.001$ \\
Sedentary behavior & 0.28 & 0.17 & 0.47 & $<0.001$ \\
Anxiety symptoms & 0.58 & 0.31 & 1.07 & 0.08 \\
Depression symptoms & 1.27 & 0.67 & 2.39 & 0.46 \\
Sleep Quality & 1.27 & 0.70 & 2.31 & 0.43 \\
\hline
\end{tabular}

$\mathrm{Cl}$, confidence interval; OR, odds ratio. Odds of those who referred MVPA $\geq 300 \mathrm{~min}$ per week vs. those that referred MVPA $<300$ min per week having depressive symptoms (BDI>12 points) and anxiety symptoms (BAl>10 points), Sleep quality ( $P S Q I \geq 6$ points.

Significant correlations were observed of MVPA and Depression symptoms $(-0.23 p<0.001)$, SB and Anxiety symptoms $(0.17 p<0.001)$, Anxiety symptoms and Depression symptoms $(0.67 p<0.001)$, Depression symptoms and Sleep quality $(0.58 p<0.001)$, and Sleep Quality and Anxiety symptoms $(0.55 p<0.001)$.

\section{DISCUSSION}

The current study aimed to compare MED and PE students during the COVID-19 pandemic, considering the time of PA (LPA and MVPA) and SB (week, weekend, and both), symptoms of anxiety and depression, and sleep quality. Our main finding indicates that MED students perform shorter MVPA, longer $\mathrm{SB}$, and have more anxiety symptoms than PE students. In addition, we observed better scores of sleep duration and habitual sleep efficiency and worse scores of use of sleeping medication and daytime dysfunction in MED students than PE students. However, the Global PSQI score was similar between groups. We also highlight the lack of differences between the first and second halves of the course in MED $\left(1^{\text {st }}\right.$ to $6^{\text {th }}$ semesters and. $7^{\text {th }}$ to $12^{\text {th }}$ semesters) and in PE ( $1^{\text {st }}$ to $4^{\text {th }}$ semesters and $5^{\text {th }}$ to $8^{\text {th }}$ semesters) considering the symptoms of anxiety and depression, LPA, MVPA, and SB (week, weekend, and total). In addition, no differences were observed for initial and final semesters in sleep quality (PSQI) for MED students, while for PE students, initial and final semesters presented differences in sleep latency and sleep disturbances components, but not for the Global PSQI score. PE students present ORs (OR = 3.87, 95\%CI 2.27-6.59 $p<0.001)$ of meeting MVPA recommendations. Significant correlations were verified of MVPA and Depression symptoms and Anxiety symptoms, as well as Anxiety symptoms and Depression symptoms, Depression symptoms and Sleep quality, and Sleep Quality and Anxiety symptoms.

The respective prevalences of elevated anxiety and depression symptoms in MED (50.4 and 51.5\%) were higher than the prevalence of anxiety (31.9\%) summarized in 17 studies $(n=$ 63,439 ) and depression $(33.7 \%)$ summarized in 14 studies ( $n=$ 44,531) (34). The absolute value prevalence of elevated anxiety and depression symptoms in PE (23.2 and 37.9\%) was similar or 
TABLE 5 | Relationship (Spearman Correlation) between MVPA, SB, Anxiety symptoms, Depression symptoms, and Sleep Quality.

\begin{tabular}{|c|c|c|c|c|c|}
\hline & MVPA & Sedentary behavior & Anxiety symptoms & Depression symptoms & Sleep Quality \\
\hline MVPA & - & $-0.20^{\star \star}$ & $-0.22^{\star \star}$ & $-0.23^{\star *}$ & -0.10 \\
\hline Sedentary behavior & $-0.20^{\star \star}$ & - & $0.17^{\star \star *}$ & $0.13^{\star}$ & 0.01 \\
\hline Anxiety symptoms & $-0.22^{\star \star}$ & $0.17^{\star \star}$ & - & $0.67^{\star \star}$ & $0.55^{\star \star}$ \\
\hline Depression symptoms & $-0.23^{\star \star}$ & $0.13^{\star \star}$ & $0.69^{\star \star}$ & - & $0.58^{\star \star}$ \\
\hline Sleep Quality & -0.10 & 0.01 & $0.55^{\star \star}$ & $0.58^{* *}$ & - \\
\hline
\end{tabular}

Spearman correlation. "indicates that the correlation is significant; $p<0.05 .{ }^{* *}$ indicates that the correlation is significant; $p<0.001$. MVPA, Moderate and vigorous physical activity.

better than presented in the meta-analysis, which could have been influenced by the MVPA and SB levels.

The relationship between lower MVPA and higher symptoms of depression and anxiety in the general population is welldescribed in the literature $(35,36)$ and in MED students $(37)$, suggesting that inactive MED students may present higher anxiety and/or depressive symptoms. Our findings confirm, at least partially, our initial hypothesis as we observed elevated physical inactivity (lower MVPA and higher SB) and higher anxiety symptoms in MED students than PE students, who were more active and reported fewer symptoms of anxiety. Some studies are available that evaluate the duration of PA and SB, and a meta-analysis including 15 studies carried out with PE students indicated that they meet the MVPA recommendation. However, this situation is not repeated with MED students, since more than two thirds of our group did not meet the MVPA recommendations (14). Although it was not our objective to investigate the reasons for these differences, it should be emphasized that PE students, in addition to having a lower workload than MED students (approximately half the workload), have curricular components with a strong practical character, which preserve an active lifestyle (38). In contrast, medical students spend more time in SB and perform less physical activity (39), which is justified in part due to a more significant load of theoretical classes.

Additionally, we highlight the extensive literature indicating that MED students and even medical professionals present impairments in mental health $(14,40)$. Although this situation may be partially attributed to the high SB time and reduced MVPA typical of MED students, associated with high study and workloads, and pressure to succeed from society and family, it may contribute to impairments in mental health.

Especially during the pandemic, a systematic review with 64 studies indicated that restrictions to reduce COVID-19 transmission affected PA and SB in the general population (7). In this scenario, studies indicate worsening mental health of MED students $(14,39)$. Since studies comparing different courses are still scarce, we compared a physically active course (PE) with a lower physically active course (MED). Our data align with other studies that evidenced that more time in MVPA and less time in SB may influence mental health $(11,41,42)$.

It is well documented that the pandemic impacts sleep quality (43). When considering Sleep Quality (PSQI), a recent metaanalysis including 31 studies $(n=5,153)$ showed poor sleep quality in $60.4 \%$ of the sample analyzed (44), which is higher than our results in MED (54.0\%) and PE (44.2\%) students. Even though we verified significant differences between the components Habitual sleep efficiency, use of sleeping medication, and daytime dysfunction, the global PSQI score did not present differences. A recent study showed that the use of the internet, fear of leaving the house, and self-medication were the most common sleeping difficulties (45).

Finally, from a constructive perspective, our study allows us to speculate on the importance of organizing university environments, especially those used by medical students, to favor students reaching the PA recommendations and reducing their SB. In fact, a recent study highlighted the necessity of shared responsibility for students to perform more time in PA that resides at a political level, in welfare organizations, and in the educational institutions (46). One example of action is flexible learning spaces at school to allow students to spend less time sitting and more time standing and moving around (47), and the possibility of accessing outdoor and nature-based PA, as this exposure has a positive effect on different emotional parameters (e.g., anxiety, depression, stress) (48). Sporting activities can also be an important strategy to increase the PA time of students, as they provide health benefits for practitioners, and also lead to the attainment of the academic performance goals that educational institutions aspire to (49).

In relation to practical applications, considering the welldescribed relation of PA and anxiety and depression symptoms, which are common in medical students (frequent problems with anxiety and depression symptoms, not meeting the PA recommendation, and presenting high $\mathrm{SB}$ ), we suggest there is a strong need to facilitate medical students to spend more time in PA and to reduce SB. We highlight the importance of providing strategies to increase the PA of university students, especially MED students, who showed poor physical activity levels (15). In this way, competitive university sports, which are already quite popular and offer recreational sports opportunities, represent alternatives to reduce SB and increase physical activity levels. Another possibility is encouraging the use of active behaviors, such as using stairs in university buildings, using spaces with dynamic characteristics for eating, classes, and computers (e.g., high benches, standing desks, or tables where the student participates in the theoretical actions while standing), and awareness of the importance of breaking prolonged sedentary behavior, among other actions. Finally, we suggest a strong need to facilitate medical students to spend more time on PA and to reduce $S B$. 


\section{Strengths and Limitations}

The strengths of this study included university students with different characteristics of PA (MED and PE), with high COVID-19 exposure in São Paulo City. Our study is not free of limitations. First, we included only one university. Second, despite the wide use of self-report tools for PA and SB measures, mental health may underestimate our findings. Finally, we could not investigate possible psychiatric conditions, such as a diagnosis of depression or anxiety disorders, in more detail.

\section{CONCLUSION}

In conclusion, our results indicate that MED students spend less time in MVPA and more time in SB than PE students and presented worse mental health in the pandemic situation imposed by COVID-19.

\section{DATA AVAILABILITY STATEMENT}

The raw data supporting the conclusions of this article will be made available by the authors, without undue reservation.

\section{REFERENCES}

1. Kraemer MUG, Yang CH, Gutierrez B, Wu CH, Klein B, Pigott DM, et al. The effect of human mobility and control measures on the COVID-19 epidemic in China. Science. (2020) 368:493-7. doi: 10.1126/science.abb4218

2. Okuyan CB, Begen MA. Working from home during the COVID-19 pandemic, its effects on health, and recommendations: the pandemic and beyond. Perspect Psychiatr Care. 1-7. (2021). doi: 10.1111/ppc.12847 [Epub ahead of print].

3. Liu HL, Lavender-Stott ES, Carotta CL, Garcia AS. Leisure experience and participation and its contribution to stress-related growth amid COVID-19 pandemic. Leisure Studies. 1-15. (2021). doi: 10.1080/02614367.2021.1942526 [Epub ahead of print].

4. Viner RM, Russell SJ, Croker H, Packer J, Ward J, Stansfield C, et al. School closure and management practices during coronavirus outbreaks including COVID-19: a rapid systematic review. Lancet Child Adolesc Health. (2020) 4:397-404. doi: 10.1016/S2352-4642(20)30095-X

5. Caspersen CJ, Powell KE, Christenson GM. Physical activity, exercise, and physical fitness: definitions and distinctions for health-related research. Public Health Rep. (1985) 100:126-31.

6. SBRN. Letter to the editor: standardized use of the terms "sedentary" and "sedentary behaviours". Appl Physiol Nutr Metab. (2012) 37:5402. doi: 10.1139/h2012-024

7. Stockwell S, Trott M, Tully M, Shin J, Barnett Y, Butler L, et al. Changes in physical activity and sedentary behaviours from before to during the COVID19 pandemic lockdown: a systematic review. BMJ Open Sport Exerc Med. (2021) 7:e000960. doi: 10.1136/bmjsem-2020-000960

8. Firth J, Siddiqi N, Koyanagi A, Siskind D, Rosenbaum S, Galletly C, et al. The Lancet Psychiatry Commission: a blueprint for protecting physical health in people with mental illness. Lancet Psychiatry. (2019) 6:675712. doi: 10.1016/S2215-0366(19)30132-4

9. Chekroud SR, Gueorguieva R, Zheutlin AB, Paulus M, Krumholz HM, Krystal $\mathrm{JH}$, et al. Association between physical exercise and mental health in 1.2 million individuals in the USA between 2011 and 2015: a cross-sectional study. Lancet Psychiatry. (2018) 5:739-46. doi: 10.1016/S2215-0366(18)30227-X

\section{ETHICS STATEMENT}

The studies involving human participants were reviewed and approved by Ethics and Research Committee of Santo Amaro University (approval number: 4.049.214). The patients/participants provided their written informed consent to participate in this study.

\section{AUTHOR CONTRIBUTIONS}

TM and KS: conceptualization, methodology, formal analysis, investigation, writing original draft, writing review and editing, and visualization. TG, AS, LN, and AB: writing original draft and writing review editing. SG: formal analysis and writing review editing. CF: conceptualization, methodology, writing original draft, and writing review editing. FR: writing review editing. LN: conceptualization, methodology, formal analysis, writing original draft, and writing review, supervision. All authors contributed to the article and approved the submitted version.

\section{FUNDING}

The work was supported by the Grants 2020/08869-0, 2021/13699-9, 2021/14033-4 by São Paulo Research Foundation (FAPESP) in Brazil.

10. Piercy KL, Troiano RP, Ballard RM, Carlson SA, Fulton JE, Galuska DA, et al. The Physical Activity Guidelines for Americans. JAMA. (2018) 320:20208. doi: 10.1001/jama.2018.14854

11. Schuch FB, Bulzing RA, Meyer J, Vancampfort D, Firth J, Stubbs B, et al. Associations of moderate to vigorous physical activity and sedentary behavior with depressive and anxiety symptoms in self-isolating people during the COVID-19 pandemic: a cross-sectional survey in Brazil. Psychiatry Res. (2020) 292:113339. doi: 10.1016/j.psychres.2020.113339

12. Xiong JQ, Lipsitz O, Nasri F, Lui LMW, Gill H, Phan L, et al. Impact of COVID-19 pandemic on mental health in the general population: a systematic review. J Affect Disord. (2020) 277:55-64. doi: 10.1016/j.jad.2020. 08.001

13. Mittal R, Su L, Jain R. COVID-19 mental health consequences on medical students worldwide. J Community Hosp Intern Med Perspect. (2021) 11:2968. doi: 10.1080/20009666.2021.1918475

14. Mendes TB, Souza KC, França CN, Rossi FE, Santos RPG, Duailibid $\mathrm{K}$, et al. Medical student with higher time of physical activity present lower anxiety and depression symptoms during the COVID-19 pandemic. Braz J Sports Med. (2021) 27:6. doi: 10.1590/1517-8692202127062021_ 0059

15. Castro O, Bennie J, Vergeer I, Bosselut G, Biddle SJ. How sedentary are university students? A systematic review and meta-analysis. Prev Sci. (2020) 21:332-43. doi: 10.1007/s11121-020-01093-8

16. Rotenstein LS, Ramos MA, Torre M, Segal JB, Peluso MJ, Guille C, et al. Prevalence of depression, depressive symptoms, and suicidal ideation among medical students: a systematic review and meta-analysis. JAMA. (2016) 316:2214-36. doi: 10.1001/jama.2016.17324

17. Pacheco JP, Giacomin HT, Tam WW, Ribeiro TB, Arab C, Bezerra IM, et al. Mental health problems among medical students in Brazil: a systematic review and meta-analysis. Revista brasileira de psiquiatria (São Paulo, Brazil : 1999). 2017 39:369-78. doi: 10.1590/1516-4446-2017-2223

18. da Silva VT, Silva LR, Oliveira VGB, Ramson BP, Caputo EL, da Silva MC. Nível de atividade física de estudantes de educação física no Brasil: uma revisão sistemática. Revista Brasileira de Atividade Física \& Saúde. (2021) 26:1-8. doi: 10.12820/rbafs.26e0197 
19. Lynch D. Personal journey and perspective from psychiatric nurse and medical student to intern doctor during COVID-19. Ir J Psychol Med. (2020) 37:178-80. doi: $10.1017 / \mathrm{ipm} .2020 .39$

20. Matsudo S, Araújo T, Marsudo V, Andrade D, Andrade E, Braggion G. Questinário internacional de atividade flsica (IPAQ): estudo de validade e reprodutibilidade no Brasil. Rev bras ativ fis saúde. (2001) 6:6-18. doi: 10.12820/rbafs.v.6n2p5-18

21. Craig CL, Marshall AL, Sjöström M, Bauman AE, Booth ML, Ainsworth BE, et al. International physical activity questionnaire: 12-country reliability and validity. Med Sci Sports Exerc. (2003) 35:1381-95. doi: 10.1249/01.MSS.0000078924.61453.FB

22. Beck AT, Epstein N, Brown G, Steer RA. An inventory for measuring clinical anxiety: psychometric properties. J Consult Clin Psychol. (1988) 56:893. doi: 10.1037/0022-006X.56.6.893

23. Beck AT, Ward C, Mendelson M, Mock J, Erbaugh J. Beck depression inventory (BDI). Arch Gen Psychiatry. (1961) 4:56171. doi: 10.1001 /archpsyc. 1961.01710120031004

24. Fydrich T, Dowdall D, Chambless DL. Reliability and validity of the Beck Anxiety Inventory. J Anxiety Disord. (1992) 6:55-61. doi: 10.1016/0887-6185(92)90026-4

25. Cunha JA. Manual da versão em português das Escalas Beck. São Paulo: casa do psicólogo (2001) 256.

26. Sæmundsson $\mathrm{BR}, \mathrm{P}^{*}$ órsdóttir $\mathrm{F}$, Kristjánsdóttir $\mathrm{H}$, Ólason $\mathrm{DP}^{*}$, Smári J, Sigurð*sson JF. Psychometric properties of the Icelandic version of the Beck Anxiety Inventory in a clinical and a student population. Eur J Psychol Assess. 27:133-41. (2011). doi: 10.1027/1015-5759/a000059

27. Gomes-Oliveira MH, Gorenstein C, Lotufo Neto F, Andrade LH, Wang YP. Validation of the Brazilian Portuguese version of the Beck Depression Inventory-II in a community sample. Braz J Psychiatry. (2012) 34:38994. doi: 10.1016/j.rbp.2012.03.005

28. Wang YP, Gorenstein C. Psychometric properties of the Beck Depression Inventory-II: a comprehensive review. Revista Brasileira de Psiquiatria. (2013) 35:416-31. doi: 10.1590/1516-4446-2012-1048

29. Shean G, Baldwin G. Sensitivity and specificity of depression questionnaires in a college-age sample. J Genet Psychol. (2008) 169:281-92. doi: 10.3200/GNTP.169.3.281-292

30. Bertolazi AN, Fagondes SC, Hoff LS, Dartora EG, da Silva Miozzo IC, de Barba MEF, et al. Validation of the Brazilian Portuguese version of the Pittsburgh sleep quality index. Sleep Med. (2011) 12:70-5. doi: 10.1016/j.sleep.2010.04.020

31. Buysse DJ, Reynolds CF III, Monk TH, Berman SR, Kupfer DJ. The Pittsburgh Sleep Quality Index: a new instrument for psychiatric practice and research. Psychiatry Res. (1989) 28:193-213. doi: 10.1016/0165-1781(89)90047-4

32. Knutson KL, Rathouz PJ, Yan LL, Liu K, Lauderdale DS. Stability of the Pittsburgh Sleep Quality Index and the Epworth Sleepiness Questionnaires over 1 year in early middle-aged adults: the CARDIA study. Sleep. (2006) 29:1503-6. doi: 10.1093/sleep/29.11.1503

33. Rao WW, Li W, Qi H, Hong L, Chen C, Li CY, et al. Sleep quality in medical students: a comprehensive meta-analysis of observational studies. Sleep Breath. (2020):1-15. doi: 10.1007/s11325-020-02020-5

34. Salari N, Hosseinian-Far A, Jalali R, Vaisi-Raygani A, Rasoulpoor S. Mohammadi M. Prevalence of stress, anxiety, depression among the general population during the COVID-19 pandemic: a systematic review and metaanalysis. Glob Health. (2020) 16:57. doi: 10.1186/s12992-020-00589-w

35. Schuch FB, Vancampfort D, Firth J, Rosenbaum S, Ward PB, Silva ES, et al. Physical activity and incident depression: a metaanalysis of prospective cohort studies. Am J Psychiatry. (2018) 175:631-48. doi: 10.1176/appi.ajp.2018.17111194

36. Schuch FB, Stubbs B, Meyer J, Heissel A, Zech P, Vancampfort D, et al. Physical activity protects from incident anxiety: a meta-analysis of prospective cohort studies. Depress Anxiety. (2019) 36:846-58. doi: 10.1002/da.22915

37. Stanford FC, Durkin MW, Stallworth JR, Blair SN. Comparison of physical activity levels in physicians and medical students with the general adult population of the United States. Phys Sportsmed. (2013) 41:8692. doi: $10.3810 / \mathrm{psm} .2013 .11 .2039$

38. Silva DAS. Nível de atividade física e fatores associados em acadêmicos de educação física de uma universidade pública do nordeste do Brasil. Revista Brasileira de Atividade Física \& Saúde. (2011) 16:193-8. doi: 10.4034/RBCS.2012.16.03.16

39. Mandic D. Bjegovic-Mikanovic V. Successful promotion of physical activity among students of medicine through motivational interview and Web-based intervention. PeerJ. (2020) 8:e9495. doi: 10.7717/peerj.9495

40. Mao Y, Zhang N, Liu J, Zhu B, He R, Wang X, et al. systematic review of depression and anxiety in medical students in China. BMC Med Educ. (2019) 19:327. doi: 10.1186/s12909-019-1744-2

41. Teychenne M, White RL, Richards J, Schuch FB, Rosenbaum S, Bennie JA. Do we need physical activity guidelines for mental health: What does the evidence tell us? Ment Health Phys Act. (2020) 18:100315. doi: 10.1016/j.mhpa.2019.100315

42. Firth J, Solmi M, Wootton RE, Vancampfort D, Schuch FB, Hoare E, et al. A meta-review of "lifestyle psychiatry": the role of exercise, smoking, diet and sleep in the prevention and treatment of mental disorders. World Psychiatry. (2020) 19:360-80. doi: 10.1002/wps.20773

43. Kaparounaki CK, Patsali ME, Mousa DPV, Papadopoulou EV, Papadopoulou KK, Fountoulakis KN. University students' mental health amidst the COVID-19 quarantine in Greece. Psychiatry Res. (2020) 290:113111. doi: 10.1016/j.psychres.2020.113111

44. Deng J. Zhou F. The prevalence of depression, anxiety, and sleep disturbances in COVID-19 patients: a meta-analysis. Ann N Y Acad Sci. (2021) 1486:90111. doi: 10.1111/nyas. 14506

45. Gualano MR, Lo Moro G, Voglino G, Bert F, Siliquini R. Effects of Covid-19 lockdown on mental health and sleep disturbances in Italy. Int J Environ Res Public Health. (2020) 17:4779. doi: 10.3390/ijerph17134779

46. Grasdalsmoen M, Eriksen HR, Lønning KJ, Sivertsen B. Physical exercise, mental health problems, and suicide attempts in university students. $B M C$ Psychiatry. (2020) 20:1-11. doi: 10.1186/s12888-020-02583-3

47. Kariippanon KE, Cliff DP, Ellis YG, Ucci M, Okely AD, Parrish AM. School flexible learning spaces, student movement behavior and educational outcomes among adolescents: a mixed-methods systematic review. J Sch Health. (2021) 91:133-45. doi: 10.1111/josh.12984

48. Corazon SS, Sidenius U, Poulsen DV, Gramkow MC, Stigsdotter UK. Psycho-physiological stress recovery in outdoor nature-based interventions: a systematic review of the past eight years of research. Int J Environ Res Public Health. (2019) 16:1711. doi: 10.3390/ijerph16101711

49. Muñoz-Bullón F, Sanchez-Bueno MJ, Vos-Saz A. The influence of sports participation on academic performance among students in higher education. Sport Manage Rev. (2017) 20:365-78. doi: 10.1016/j.smr.2016.10.006

Conflict of Interest: The authors declare that the research was conducted in the absence of any commercial or financial relationships that could be construed as a potential conflict of interest.

Publisher's Note: All claims expressed in this article are solely those of the authors and do not necessarily represent those of their affiliated organizations, or those of the publisher, the editors and the reviewers. Any product that may be evaluated in this article, or claim that may be made by its manufacturer, is not guaranteed or endorsed by the publisher.

Copyright (๐ 2021 Souza, Mendes, Gomes, Silva, Nali, Bachi, Rossi, Gil, França and Neves. This is an open-access article distributed under the terms of the Creative Commons Attribution License (CC BY). The use, distribution or reproduction in other forums is permitted, provided the original author(s) and the copyright owner(s) are credited and that the original publication in this journal is cited, in accordance with accepted academic practice. No use, distribution or reproduction is permitted which does not comply with these terms. 